\title{
Research on Static Triaxial Mechanical Properties of New CementSoil Reinforced with Polypropylene Fiber
}

\author{
Qiang Wang, ${ }^{1}$ Rui Tang, ${ }^{1}$ Qun Cheng, ${ }^{2}$ Xiankun Wang, ${ }^{1}$ and Fang-ling Liu ${ }^{2}$ \\ ${ }^{1}$ School of Civil Engineering and Architecture, Anhui University of Science and Technology, Huainan 232001, China \\ ${ }^{2}$ China Construction 4th Engineering Bureau 6th Corp. Limited, Hefei 230011, China \\ Correspondence should be addressed to Qiang Wang; wangqiang0711@163.com
}

Received 30 June 2014; Accepted 25 August 2014; Published 12 October 2014

Academic Editor: Mohd Sapuan

Copyright (c) 2014 Qiang Wang et al. This is an open access article distributed under the Creative Commons Attribution License, which permits unrestricted use, distribution, and reproduction in any medium, provided the original work is properly cited.

\begin{abstract}
Through the laboratory test, the mechanical properties of cementsoil with adding desulfurization gypsum, fly ash, and polypropylene fiber were studied. Three different percentages $(0 \%, 0.5 \%$, and $1.0 \%)$ of polypropylene fiber were mixed into new cementsoil for which the cement content is $15 \%$ of the dry soil weight, the desulfurization gypsum content is $2 \%$ of the dry soil weight, and the fly ash content is $1.0 \%$ of the dry soil weight. The new cementsoil strength reinforced with polypropylene fiber was studied by triaxial test under different polypropylene fiber mixing ratio, different age, and different confining pressure. The experimental results show that, compared with ordinary soil, the deviatoric stress and the peak shear strength reinforced with polypropylene fiber have different amplitude increase. At the same time, the internal friction angle of new cementsoil with polypropylene fiber increases slightly with the growth of the age. The stress-strain curve of the polypropylene fiber cementsoil has the typical work hardening characteristic and has the characteristics of bulge fracture.
\end{abstract}

\section{Introduction}

Soil reinforcement has been introduced into the field of geotechnical engineering for many years in order to improve the properties of ground soil in specific engineering projects. Traditional geosynthetics, such as geotextile and geogrid, have been proved to be efficient, and they are being increasingly used in geotechnical engineering and other fields [1]. They have attracted the attention of scientists worldwide, and a number of triaxial tests, unconfined compression tests, CBR tests, and direct shear tests on this subject have been conducted [2-5, 5-12]. Consoli et al., 1998 [13], added the randomly distributed fibers to cemented soil, conducted triaxial compression tests on the mixture, and concluded that the fiber reinforcement increased both the peak and residual strength and changed the cemented soil's brittle behavior to a more ductile one. The inclusion of fibers significantly changed the failure mechanism by preventing the formation of tension cracks [14]. Miller and Rifai, 2004 [15], reported that the shrinkage crack reduction and hydraulic conductivity of compacted clay soil increased with an increase in fiber content. All these investigations show that the inclusion of discrete fibers can improve the strength behavior and significantly enhance the ductility and fracture toughness of soil matrix. It has been proved that discrete fibers can be considered as good earth reinforcement material.

The interface between construction materials and soil plays an important role in many geotechnical systems including pile foundations, retaining walls, and especially reinforced soil systems. Experimental results related to the behavior of conventional geosynthetic reinforced soil showed that the geosynthetic/soil interface properties play a key role in the mechanical behavior and design of engineering [16-19].

The cementsoil material has advantages of adjustable high plasticity of improving the strength of soils, the source is very wide, and therefore they are widely used in pile foundations, retaining walls, especially reinforced soil systems, and so forth, but the cementsoil is essentially still belonging to a kind of special soils, the compressive strength is far less than concrete, the tensile strength is low, and the cementsoil is still existing in problems such as deformation when used in composite foundation. Therefore, many scholars were 
TABLE 1: Physicomechanical indexes of the soils of silty clay.

\begin{tabular}{lccccc}
\hline Index & Wet density $\mathrm{g} / \mathrm{cm}^{3}$ & Void ratio & Liquid limit $\%$ & Plastic limit \% & Water content \% \\
\hline Silty clay & 2.72 & 0.619 & 36.7 & 24.5 & 22.42 \\
\hline
\end{tabular}

TABLE 2: Chemical composition of desulfurization gypsum.

\begin{tabular}{lccccccccc}
\hline Surface water & Crystal water & Loss on ignition & $\mathrm{SiO}_{2}$ & $\mathrm{Al}_{2} \mathrm{O}_{3}$ & $\mathrm{Fe}_{2} \mathrm{O}_{3}$ & $\mathrm{CaO}$ & $\mathrm{MgO}$ & $\mathrm{K}_{2} \mathrm{O}+\mathrm{Na}_{2} \mathrm{O}$ & $\mathrm{SO}_{3}$ \\
\hline 7.96 & 14.83 & 21.21 & 1.94 & 0.9 & 0.23 & 31.31 & 0.29 & 0.18 & 43.49 \\
\hline
\end{tabular}

TABLE 3: Physical parameters of fly ash.

\begin{tabular}{lccccc}
\hline Loss on ignition & Fineness & Water demand ratio & Chloridion & Alkali ion & Free calcium oxide \\
\hline $1.9 \%$ & $10.0 \%$ & $93.0 \%$ & $0.004 \%$ & $0.71 \%$ & $0.5 \%$ \\
\hline
\end{tabular}

TABle 4: Physicomechanical parameters of polypropylene fiber.

\begin{tabular}{lcccccc}
\hline Fiber type & Density & Length & Tensile strength & Elasticity modulus & Melting point & Ultimate tensile strain rate \\
\hline Single fiber & $0.91 \mathrm{~g} / \mathrm{cm}^{3}$ & $19 \mathrm{~mm}$ & $>300 \mathrm{MPa}$ & $3793 \mathrm{MPa}$ & $160 \sim 170^{\circ} \mathrm{C}$ & $30 \% \sim 50 \%$ \\
\hline
\end{tabular}

TABLE 5: The testing program.

\begin{tabular}{lcccc}
\hline Group number & Content of cement \% & Content of desulfurization gypsum \% & Content of fly ash \% & Content of polypropylene fiber \% \\
\hline A & 15 & 2 & 1 & 0 \\
B & 15 & 2 & 1 & 0.5 \\
C & 15 & 2 & 1 & 1 \\
\hline
\end{tabular}

TABLE 6: The results of unconfined compressive strength and triaxial compressive strength test.

\begin{tabular}{|c|c|c|c|c|c|c|c|c|c|c|c|c|c|c|c|}
\hline & \multicolumn{9}{|c|}{ Compressive strength/MPa } & \multicolumn{6}{|c|}{ Intensity parameter } \\
\hline & \multicolumn{3}{|c|}{$\sigma_{3}=100 \mathrm{kPa}$} & \multicolumn{3}{|c|}{$\sigma_{3}=200 \mathrm{kPa}$} & \multicolumn{3}{|c|}{$\sigma_{3}=300 \mathrm{kPa}$} & \multicolumn{3}{|c|}{$\mathrm{c} / \mathrm{kPa}$} & \multicolumn{3}{|c|}{$\Phi\left(^{\circ}\right)$} \\
\hline & $7 \mathrm{~d}$ & $14 \mathrm{~d}$ & $28 \mathrm{~d}$ & $7 \mathrm{~d}$ & $14 \mathrm{~d}$ & $28 \mathrm{~d}$ & $7 \mathrm{~d}$ & $14 \mathrm{~d}$ & $28 \mathrm{~d}$ & $7 \mathrm{~d}$ & $14 \mathrm{~d}$ & $28 \mathrm{~d}$ & $7 \mathrm{~d}$ & $14 \mathrm{~d}$ & $28 \mathrm{~d}$ \\
\hline A & 3.8 & 5.0 & 5.2 & 4.5 & 5.5 & 5.7 & 4.8 & 5.9 & 6.5 & 650.36 & 780.2 & 810.9 & 43.2 & 44.4 & 45.9 \\
\hline B & 4.2 & 5.2 & 6.9 & 4.9 & 5.8 & 7.8 & 5.5 & 6.5 & 8.8 & 760.4 & 820.89 & 881.4 & 45.3 & 46.1 & 52.6 \\
\hline $\mathrm{C}$ & 5.0 & 6.9 & 7.4 & 5.7 & 7.4 & 8.9 & 6.4 & 8.4 & 9.7 & 801.5 & 899.4 & 919.6 & 45.4 & 50.5 & 53.8 \\
\hline
\end{tabular}

seeking to improve the performance of cementsoil, such as [16-19].

At present, the fiber as a kind of engineering materials was widely used in the concrete; some scholars also added the fiber to the soil. It has some advantages with adding the polypropylene fiber into cementsoil, such as improving the tensile strength of soil, stopping the microcracks or original defects extension, delaying the occurrence of cracks, and improving the ability of deformation, toughness, and resistance of the matrix. In order to get better performance of composite cementsoil, the desulfurization gypsum, fly ash, and polypropylene fiber were added into ordinary cement, and the mechanical properties of new cementsoil with adding desulfurization gypsum and fly ash and polypropylene fiber were studied under different confining pressure.

Based on new cementsoil reinforcement technology research, the author put forward the new concept with the polypropylene fiber reinforced cementsoil. This paper selects polypropylene fiber as reinforced material. The mechanical properties of the new cementsoil were studied through static triaxial test according to the polypropylene fiber content, different confining pressure, and different age. It has great reference value in the engineering application.

\section{Materials and Methods}

2.1. Materials. The silty clay soil used in the present tests was obtained from a foundation in Zhujiang New Town, Guangzhou, China. It was air-dried and broken into pieces to pass through a $2 \mathrm{~mm}$ sieve. Its physical properties were listed in Table 1. The desulfurization gypsum and fly ash were used from Pingwei power plant, Huainan, Anhui, China. The chemical composition of desulfurization gypsum was shown in Table 2. The chemical components of fly ash were shown in Table 3. The used polypropylene fiber was shown in Figure 1. The physical and mechanical performance parameters were shown in Table 4. The cement used P.O. 42.5 ordinary Portland cement; its stability and strength 


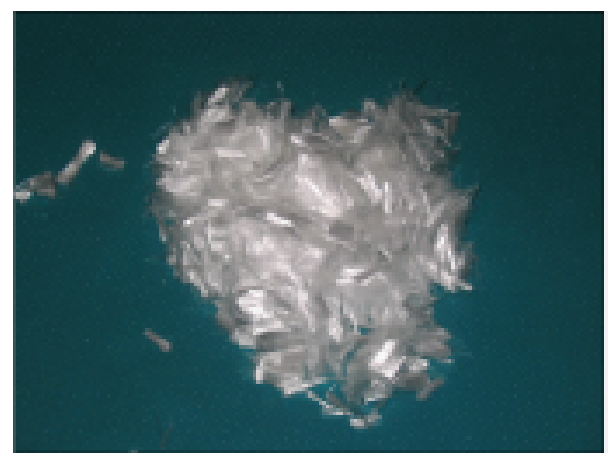

FIGURE 1: The polypropylene fiber.
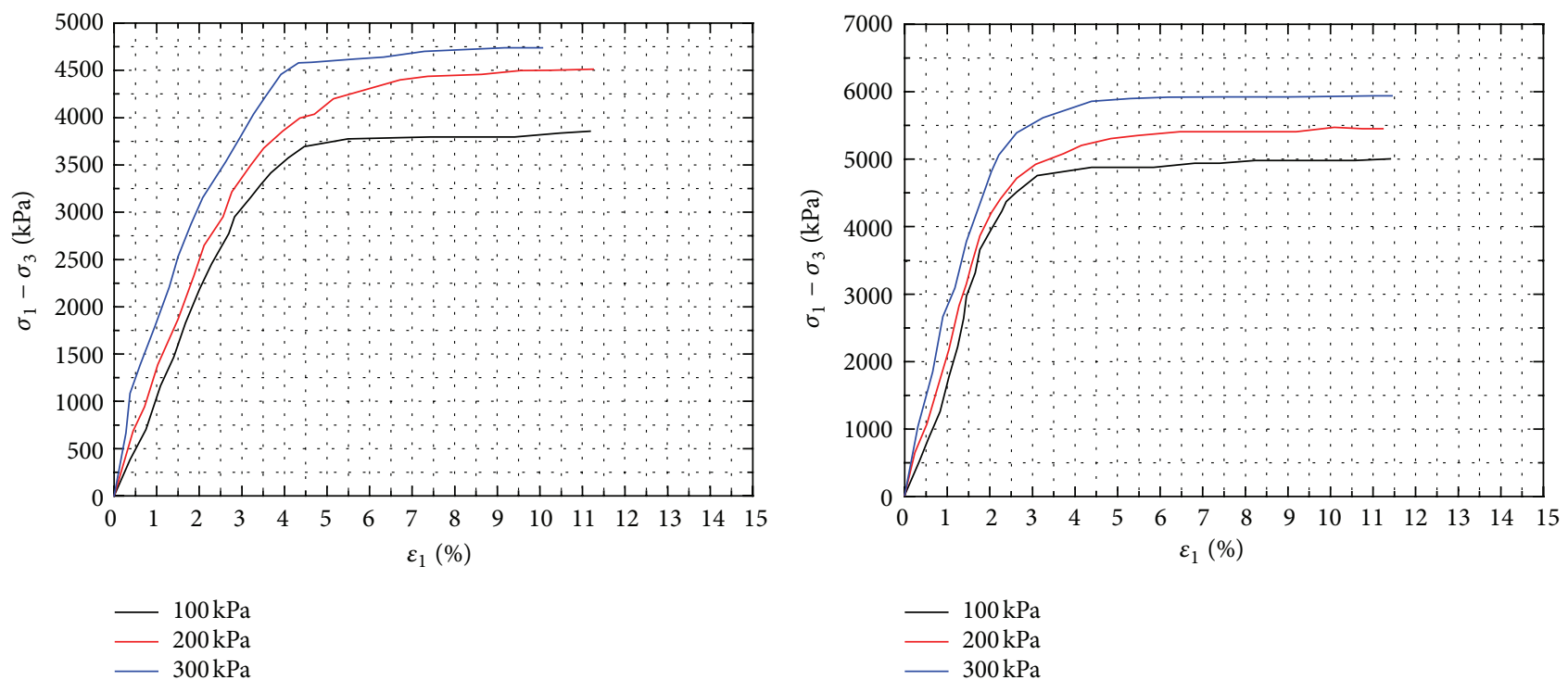

(a) 7-day age

(b) 14-day age

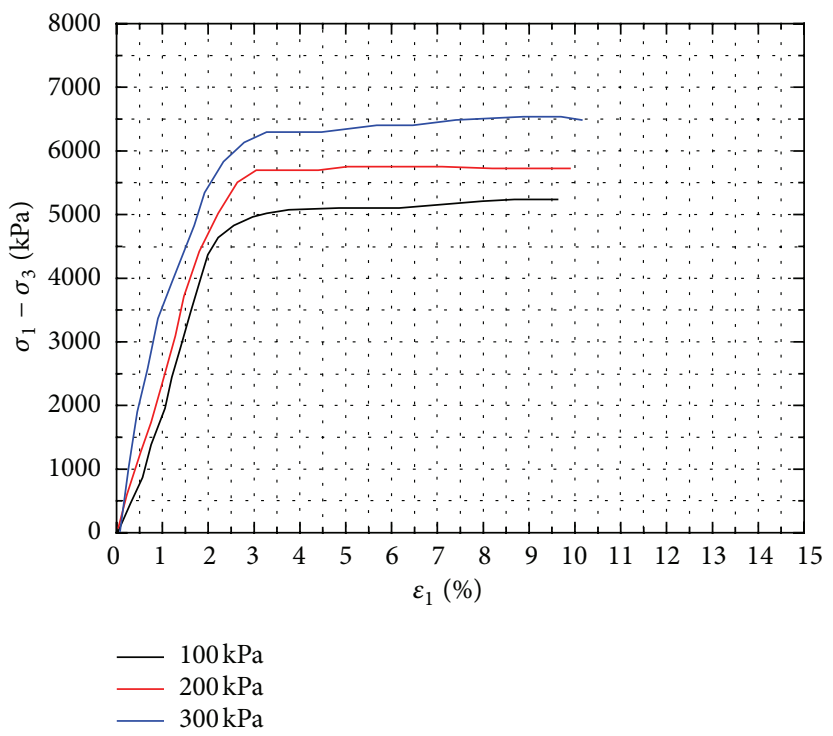

(c) 28-day age

FIGURE 2: Stress and strain curve of no polypropylene fiber. 


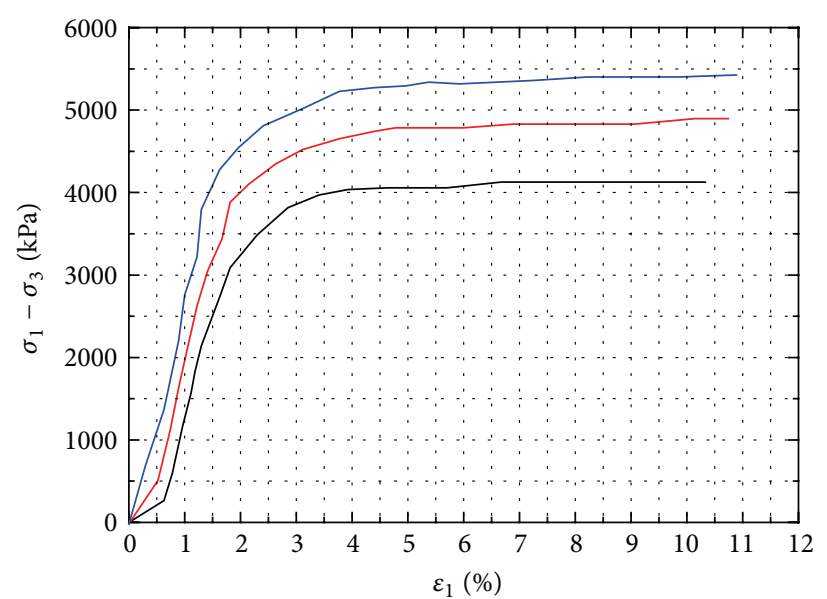

$100 \mathrm{kPa}$
$-200 \mathrm{kPa}$
$-300 \mathrm{kPa}$

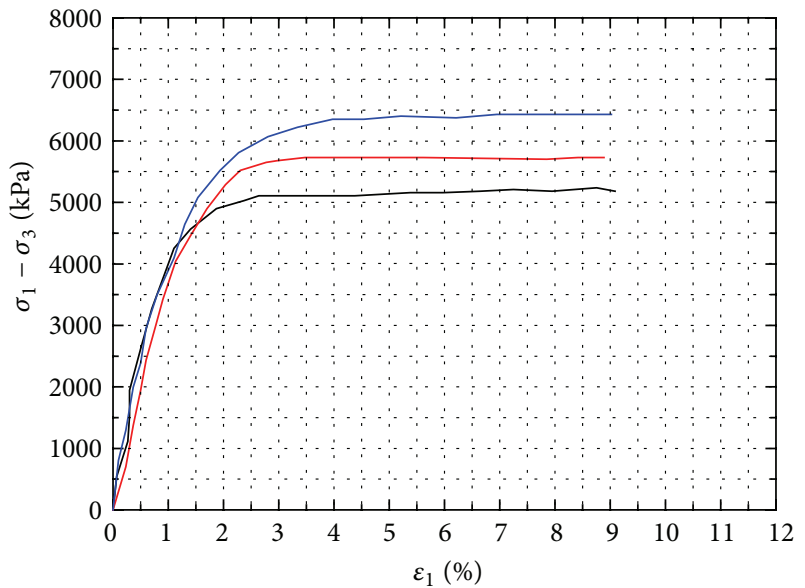

$-100 \mathrm{kPa}$
$-200 \mathrm{kPa}$
$-300 \mathrm{kPa}$

(a) 7-day age

(b) 14-day age
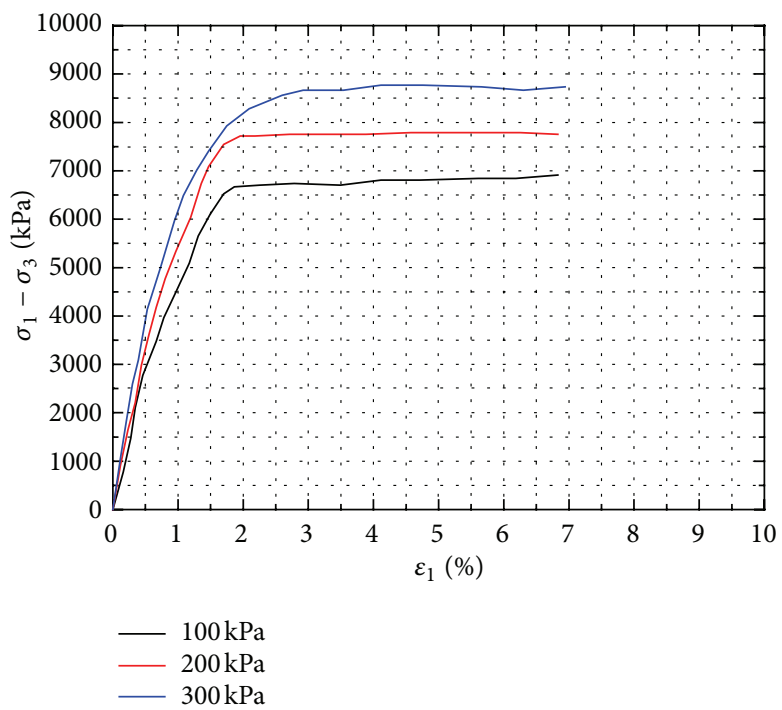

(c) 28-day age

FIGURE 3: Stress-strain curve of adding $0.5 \%$ polypropylene fiber.

of adhesive and additives satisfied the requirements of the national code being in force presently "General Portland Cement Regulation (GB175-1999)". And the test water was tap water.

\subsection{Specimen Preparation and Maintenance. The polypropy-} lene fiber content was $0.0 \%, 0.5 \%$, and $1.0 \%$ of cement weight, respectively; then throw the dry soil, desulfurization gypsum, polypropylene fiber, fly ash, and cement into a blender, mix them for five minutes, then add water, and continue to mix them for ten minutes together. Remove mixture into a mold, and the specimen was divided into three layers by hammer legal method. The mold is $39.1 \mathrm{~mm}$ in diameter and $80 \mathrm{~mm}$ in height. The specimen was demoulded after 24 hours and then maintained into the water bath up to design age.
2.3. Methods. According to the content of polypropylene fiber and age, the nine kinds of experiment conditions were designed and the confining pressures were $100 \mathrm{kPa}, 200 \mathrm{kPa}$, and $300 \mathrm{kPa}$. In order to reduce the discreteness of the test results, the same three groups parallel specimens were tested under the same confining pressure. The laboratory test was according to the "standard for soil test method" (GB/T501232002). The triaxial test instrument used for STSZ-2 strain controlled triaxial apparatus, the testing program was shown in Table 5, and the water-cement ratio was 0.5 .

\section{Results and Analysis}

3.1. The Age Influence for the New Cementsoil Strength. The unconfined compression strength and the unconsolidation 


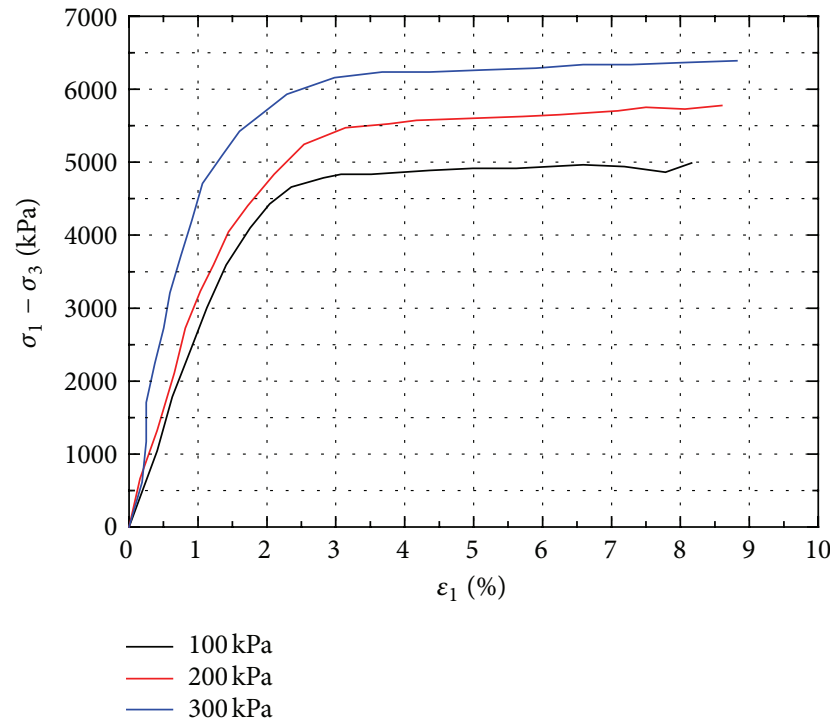

(a) 7-day age

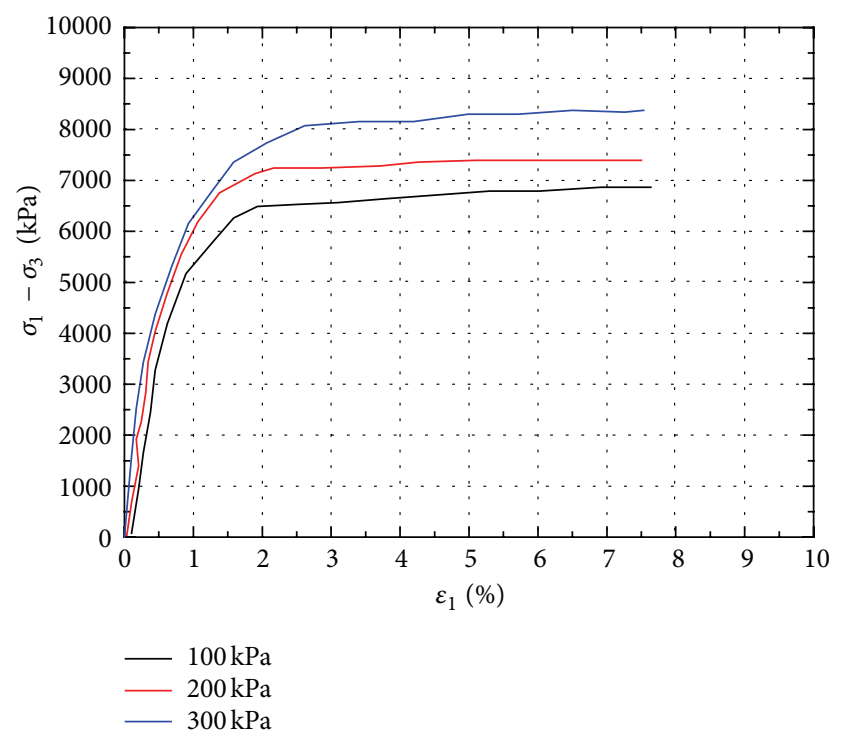

(b) 14-day age

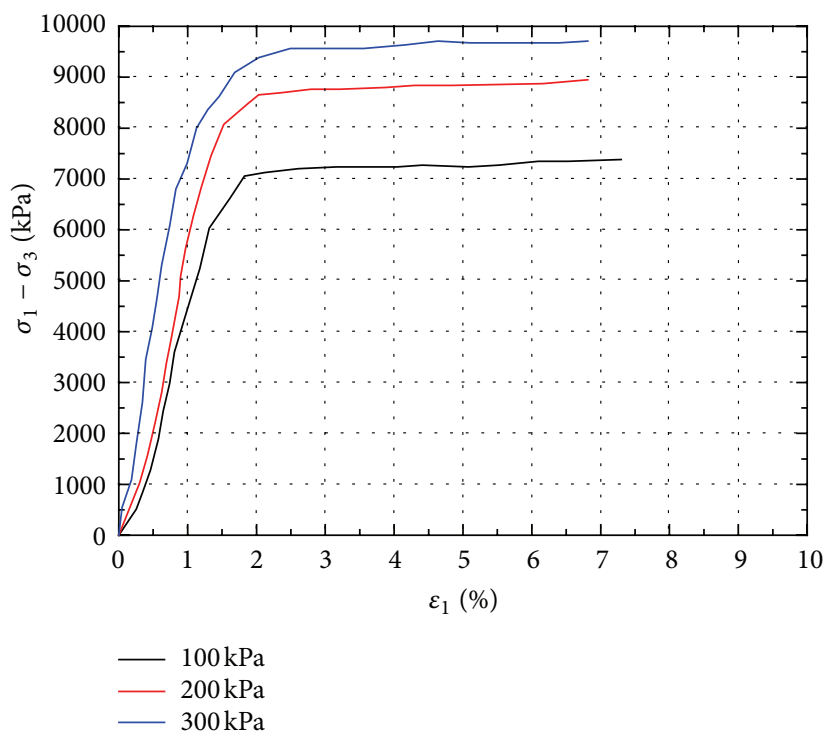

(c) 28-day age

FIGURE 4: Stress-strain curve of adding 1.0\% polypropylene fiber.

undrained triaxial shear strength of new cementsoil were the most commonly and important parameters used in bearing capacity design of mixing piles. So these properties were the main content of the laboratory test. The unconfined compression strength results of the new cementsoil in different age were shown in Table 6.

According to specimen failure stress of the new cementsoil with polypropylene fiber and desulphurization gypsum and fly ash under different confining pressure, the failure envelope was drawn. Thus the cohesion and internal friction angle were concluded under the unconsolidation undrained condition at different age. Those intensity parameters were shown in Table 6.
The stress-strain curves of polypropylene fiber reinforced new cementsoil were shown in Figures 2, 3, and 4. Firstly, the stress-strain curve shape of the polypropylene fiber reinforced new cementsoil was basic hyperbolic shape. Secondly, the compressive strength of polypropylene fiber reinforced new cementsoil was increasing with the axial strain increasing, the vast majority had no obvious peak, and the stressstrain characteristics were strain hardening model. Thirdly, the principal stress difference of adding polypropylene fiber cementsoil was increasing with the increase of polypropylene fiber content under the same confining pressure. Fourthly, the principal stress difference also increased with the growth of the age under the same confining pressure. Fifthly, through 


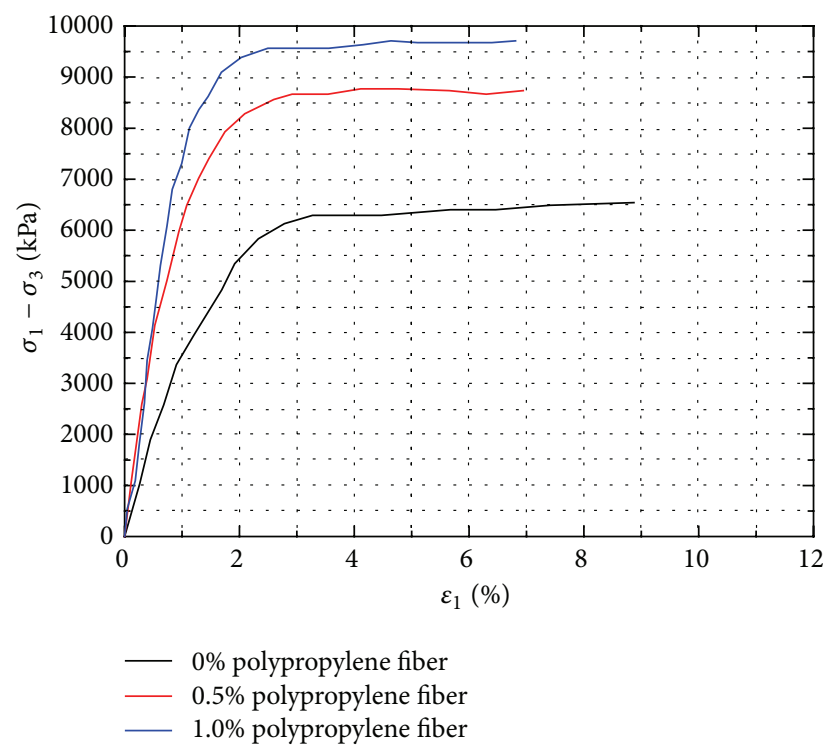

FIgURE 5: The limit deviatoric stress of different polypropylene fiber content under confining pressure (300 kPa).

the analysis of stress-strain curve, under the axial strain between $4 \%$ and $6 \%$, the stress was close to the limit value, and then the stress-strain curve was in a level state; the stress did not increase with the increase of strain and had obvious yield stage. Sixthly, the strength of the specimen increases with the increase of confining pressure; when axial strain is small, confining pressure effect on the strength is very small, and this showed that, in the case of minor axial strain, the influence of confining pressure had not yet to play; that is to say, under the small axial strain, the polypropylene fiber in the specimens had not been stretched to its state before the consolidation, so the polypropylene fiber had not played a role. And with the increasing of axial strain, the fiber had been stretched further until more than its initial state and the friction effect between polypropylene fiber and the soil had to play, and the greater the axial deformation, the greater the confining pressure effect on the deviatoric stress.

3.2. Limiting Deviatoric Stress. The limiting deviatoric stress of new cementsoil was concerned with the polypropylene fiber content, age, and confining pressure; the limiting deviatoric stress of the new cementsoil was shown in Figures 5 and 6 under different test conditions.

Some conclusions could be seen from Figure 6. Firstly, the curing age had great influences on the strength of the cementsoil; for the same polypropylene fiber content cementsoil, the strength increased significantly with the curing age, especially the curing age of 28-day; its strength was almost 1.5 times as strong as 7-day or even more. Secondly, the strength was mainly affected by polypropylene fiber content and curing age. The limiting deviatoric stress of new cementsoil increased with the increasing polypropylene fiber content and curing age.
3.3. Intensity Index. The calculation methods of the intensity parameters of new cementsoil have two kinds; one kind is Mohr circle construct under different confining pressure; namely, the strength parameters of soil can use the strength envelope to calculate. Another is formed of $\mathrm{p}-\mathrm{q}$ chart to calculate the strength parameters of the soil. This paper used the strength envelope method to calculate the intensity parameters of the soil, as shown from Figures 7, 8, and 9. The $C_{u}$ is cohesion force, and $\Phi_{u}$ is internal fractional angle.

Some conclusions could be seen from Figure 7 to Figure 9. Firstly, for curing age 7-day specimen, $\Phi_{u}$ value increased slightly with the increase of polypropylene fiber content. In the curing ages of 14-day and 28-day, $\Phi_{u}$ value increased with the increasing of polypropylene fiber and was relatively stable. Secondly, the curing age directly affects the $c$ value of the specimen, and the growth of the $c$ value of the curing ages of 14-day and 28-day was larger than that of the curing age of 7-day; the main reason was that the active ingredient in cement, desulfurization gypsum, and fly ash could be gelation reaction with the carbonate of water and soil which produced the effect to improve the strength of the soil by carbonate.

\section{Conclusion}

Firstly, the strength of polypropylene fiber reinforced new cementsoil gradually increased with the increasing of axial strain. The vast majority of specimens had no obvious peak value, and the stress-strain characteristics had been shown as strain hardening model.

Secondly, after joining the polypropylene fiber, under the same confining pressure, the principal stress difference increased with the increasing of polypropylene fiber content; the stress of most of the specimens was close to the limit when 


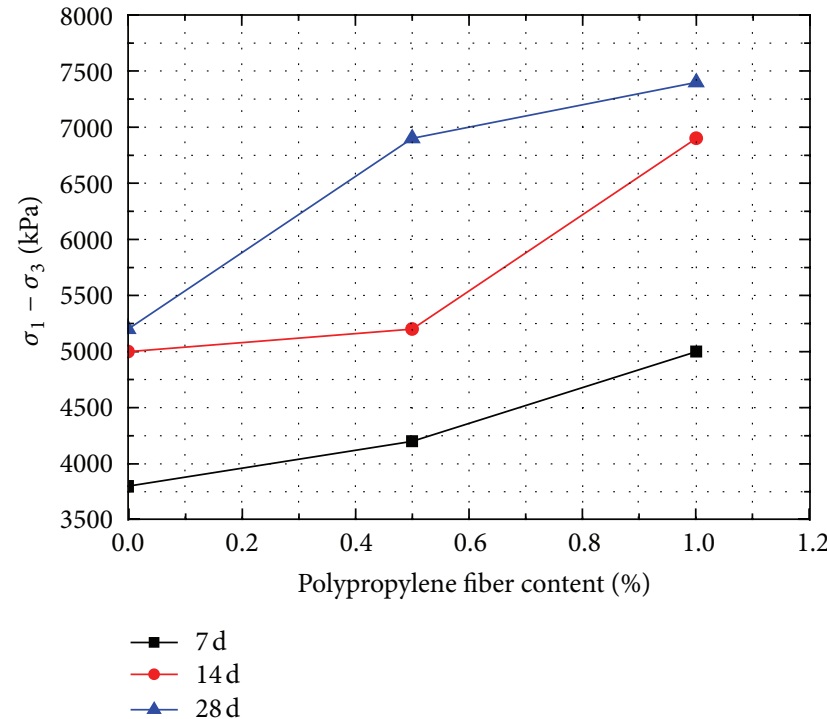

(a) Confining pressure of $100 \mathrm{kPa}$

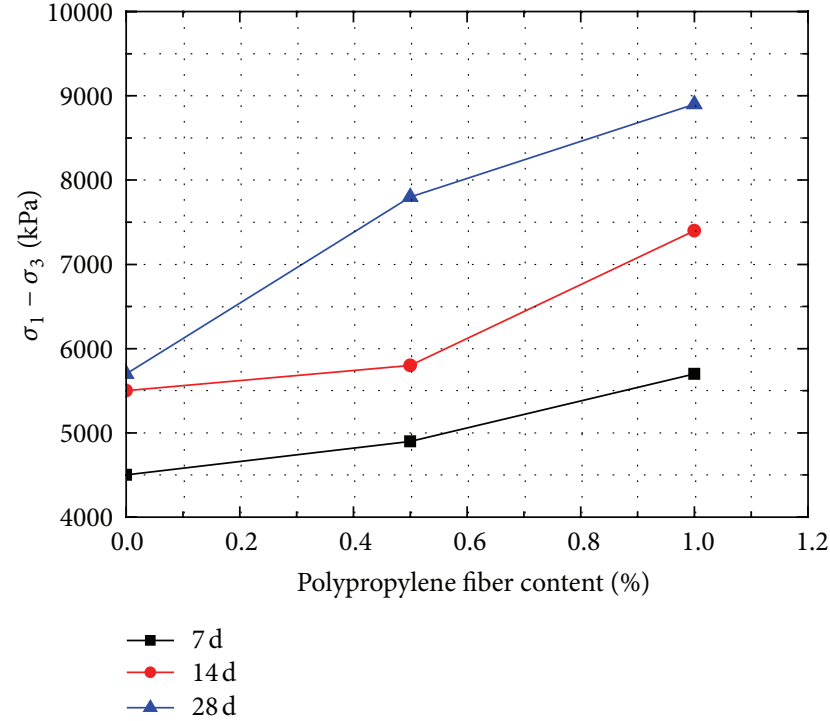

(b) Confining pressure of $200 \mathrm{kPa}$

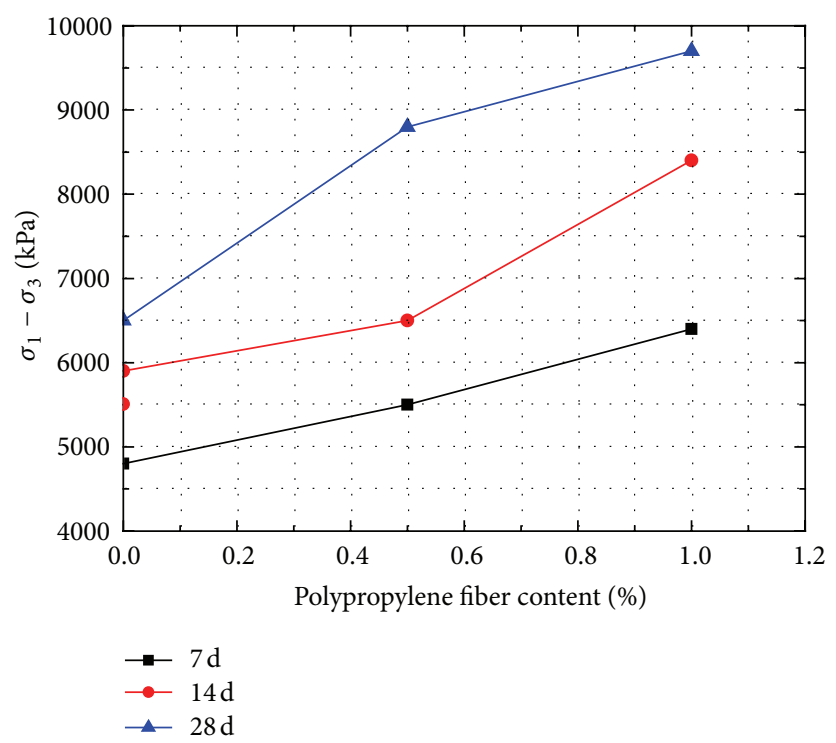

(c) Confining pressure of $300 \mathrm{kPa}$

FIGURE 6: The limit deviatoric stress change with dosage under different confining pressure.

the strain was in the range of $4 \%$ to $6 \%$. Then the stress-strain curve was in level state; when the strain increases, the stress is not increased.

Thirdly, with the growth of the curing age, internal friction angle of the polypropylene fiber new cementsoil increased slightly, but the overall increase was small.

Fourthly, when the axial strain was small, the relationship curve of the principal stress difference $\left(\sigma_{1}-\sigma_{3}\right)$ and axial strain $\varepsilon$ were almost coincident, and the effect of polypropylene fiber reinforcement is not obvious. However, with the increasing of axial strain, when the extension of polypropylene fiber exceeds the natural state of the fiber preparation, the polypropylene fiber began to play a role in cementsoil, and the effect on the strength of cementsoil is more obvious.

\section{Conflict of Interests}

The authors declare that there is no conflict of interests regarding the publication of this paper.

\section{Acknowledgments}

The work described in this paper was supported by the Outstanding Youth Fund of the Education Department of 


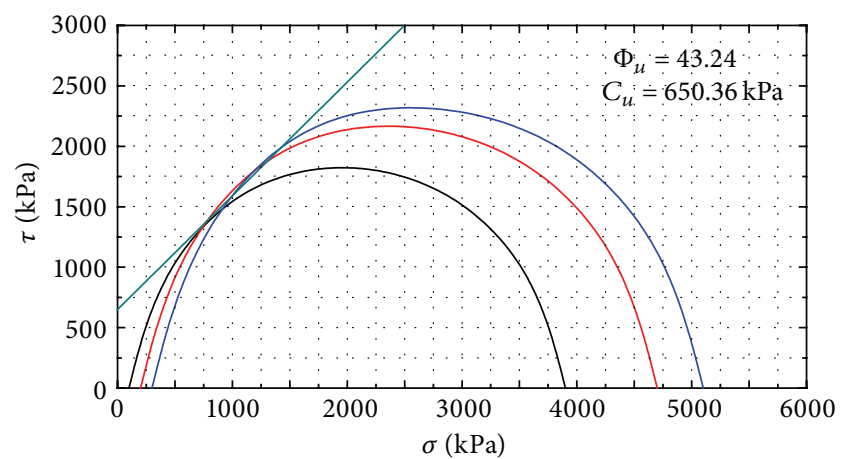

(a) 7-day age

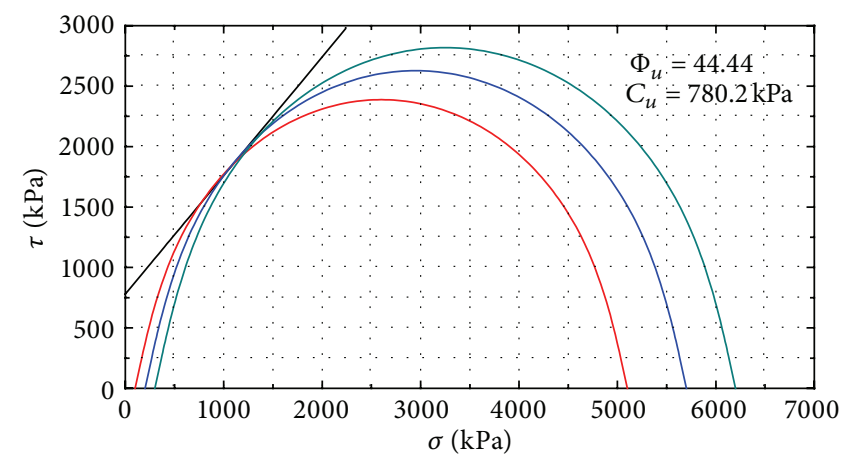

(b) 14-day age

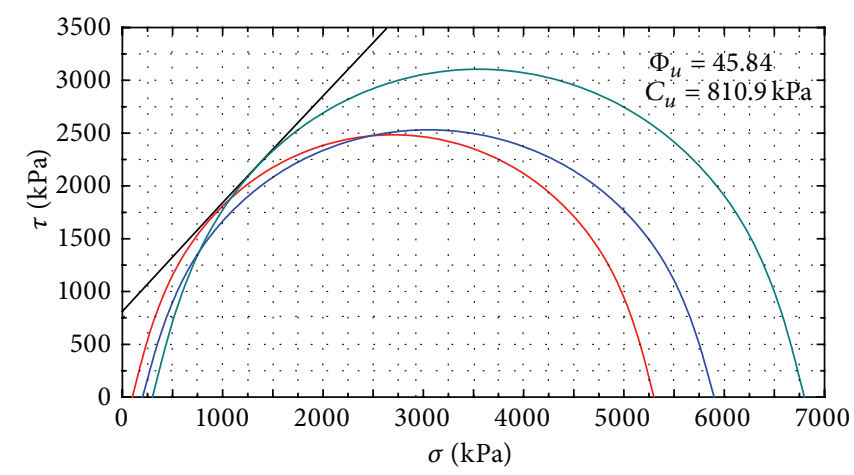

(c) 28-day age

FIGURE 7: Polypropylene fiber content $0 \%$ unconsolidation undrained shear strength envelope.

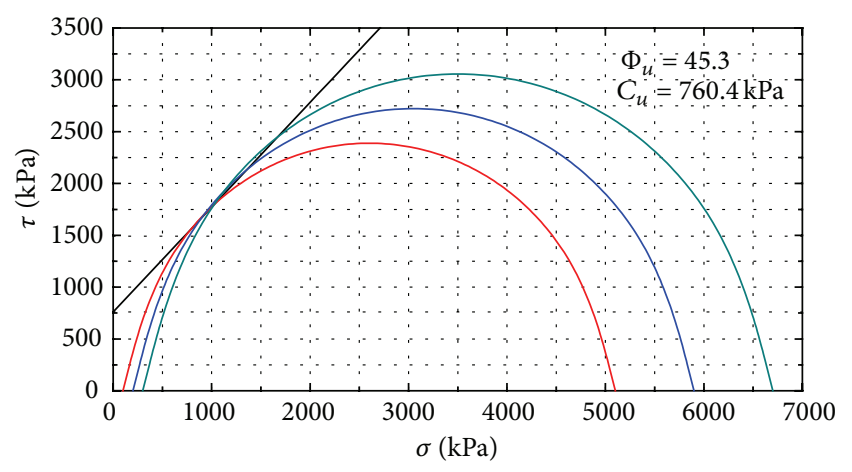

(a) 7-day age

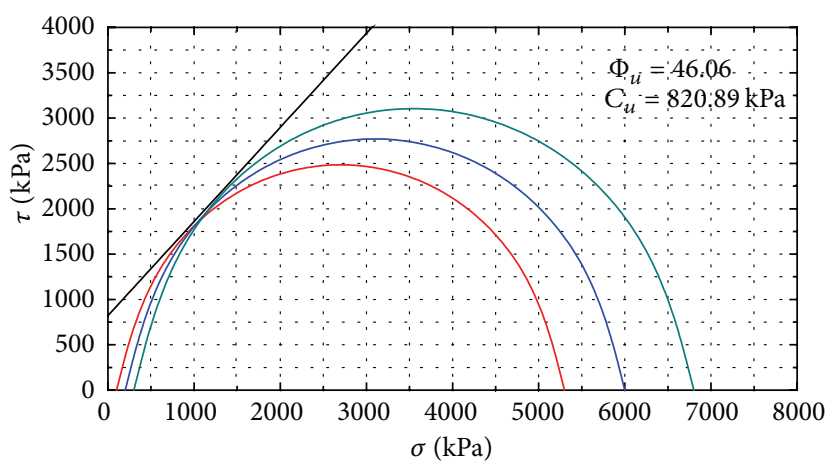

(b) 14-day age

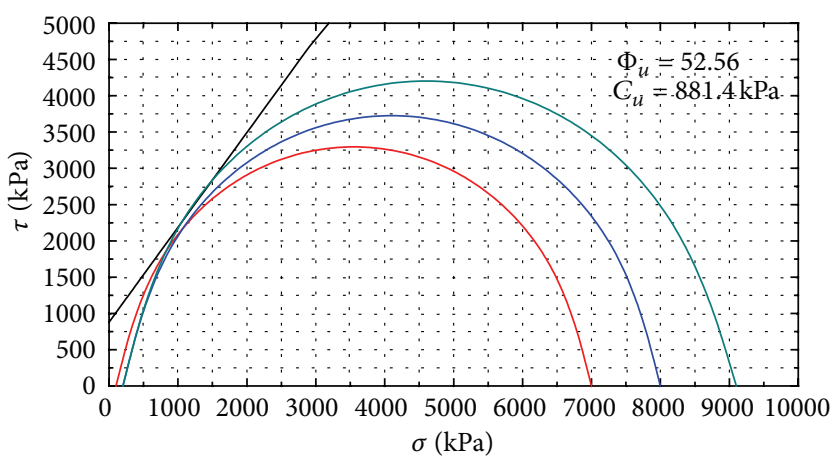

(c) 28-day age

FIGURE 8: Polypropylene fiber content $0.5 \%$ unconsolidation undrained shear strength envelope. 


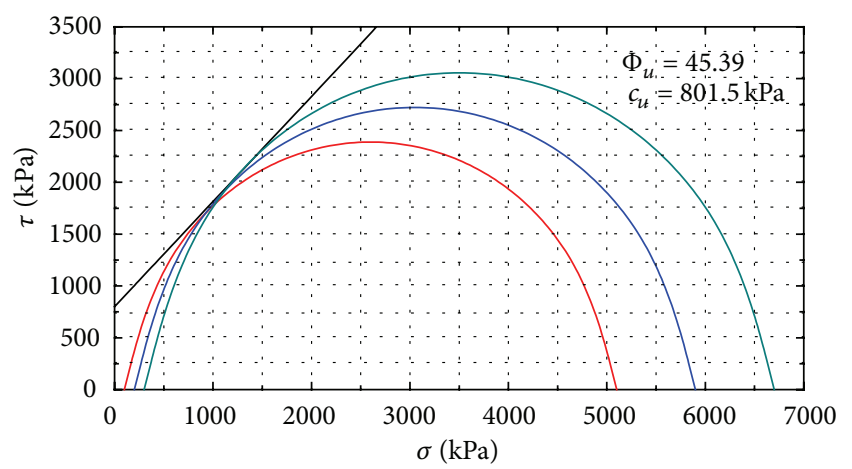

(a) 7-day age

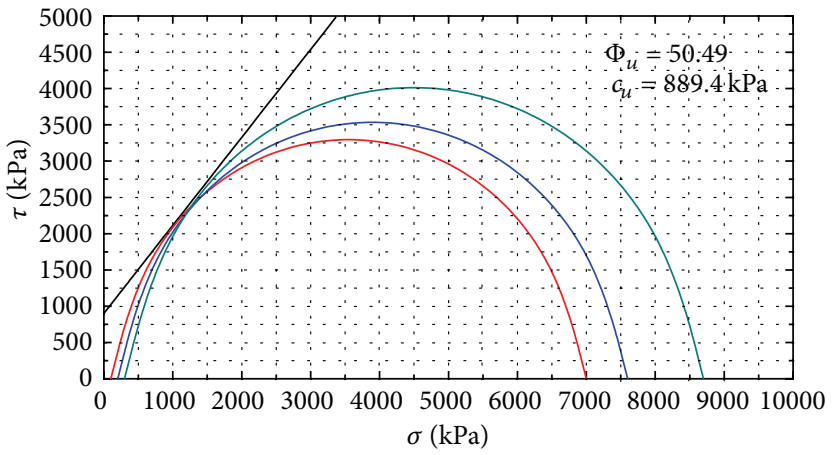

(b) 14-day age

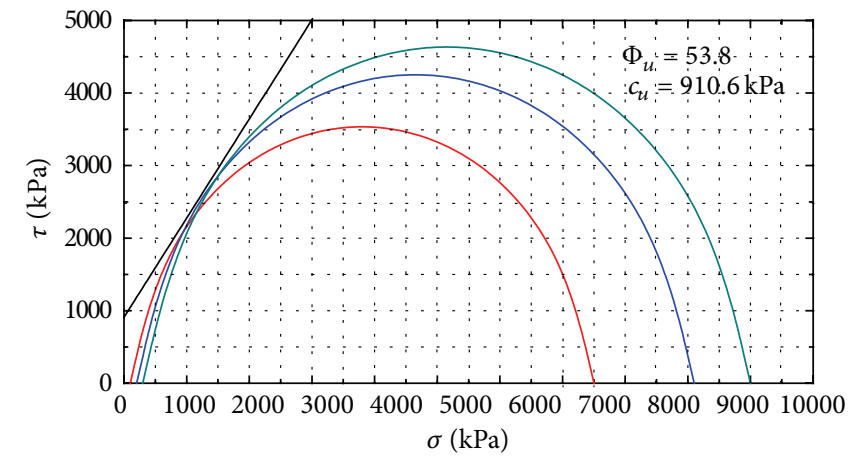

(c) 28-day age

Figure 9: Polypropylene fiber content 1.0\% unconsolidated undrained shear strength envelope.

Anhui Province (no. 2011SQRL045), Master/Doctor Fund of the Anhui University of Science and Technology, Young Scholar Fund of the Anhui University of Science and Technology, the National Natural Science Foundation of China (no. 51208005), the Fund of China State Construction Engineering Corporation (no. CSCEC-2013-Z-10), and Project funded by China Postdoctoral Science Foundation (NO.2014M561806).

\section{References}

[1] P. V. Long, D. T. Bergado, and H. M. Abuel-Naga, "Geosynthetics reinforcement application for tsunami reconstruction: evaluation of interface parameters with silty sand and weathered clay," Geotextiles and Geomembranes, vol. 25, no. 4-5, pp. 311323, 2007.

[2] G. Ranjan, R. M. Vasan, and H. D. Charan, "Probabilistic analysis of randomly distributed fiber-reinforced soil," Journal of Geotechnical Engineering, vol. 122, no. 6, article 9546, pp. 419426, 1996.

[3] S. R. Kaniraj and V. G. Havanagi, "Behavior of cement-stabilized fiber-reinforced fly ash-soil mixtures," Journal of Geotechnical and Geoenvironmental Engineering, vol. 127, no. 7, pp. 574-584, 2001.

[4] R. L. Santoni, J. S. Tingle, and S. L. Webster, "Engineering properties of sand-fiber mixtures for road construction," Journal of Geotechnical and Geoenvironmental Engineering, vol. 127, no. 3, pp. 258-268, 2001.

[5] S.-S. Park, "Effect of fiber reinforcement and distribution on unconfined compressive strength of fiber-reinforced cemented sand," Geotextiles and Geomembranes, vol. 27, no. 2, pp. 162-166, 2009.

[6] T. Yetimoglu and O. Salbas, "A study on shear strength of sands reinforced with randomly distributed discrete fibers," Geotextiles and Geomembranes, vol. 21, no. 2, pp. 103-110, 2003.

[7] T. Yetimoglu, M. Inanir, and O. E. Inanir, "A study on bearing capacity of randomly distributed fiber-reinforced sand fills overlying soft clay," Geotextiles and Geomembranes, vol. 23, no. 2, pp. 174-183, 2005.

[8] Y. Cai, B. Shi, C. W. W. Ng, and C.-S. Tang, "Effect of polypropylene fibre and lime admixture on engineering properties of clayey soil," Engineering Geology, vol. 87, no. 3-4, pp. 230-240, 2006.

[9] C. Tang, B. Shi, W. Gao, Y. Cai, and J. Liu, "Study on effects of sand content on strength of polypropylene fiber reinforced clay soil," Chinese Journal of Rock Mechanics and Engineering, vol. 26, supplement 1, pp. 2968-2973, 2007.

[10] C. Tang, B. Shi, W. Gao, F. Chen, and Y. Cai, "Strength and mechanical behavior of short polypropylene fiber reinforced and cement stabilized clayey soil," Geotextiles and Geomembranes, vol. 25, no. 3, pp. 194-202, 2007.

[11] G. M. Latha and V. S. Murthy, "Effects of reinforcement form on the behavior of geosynthetic reinforced sand," Geotextiles and Geomembranes, vol. 25, no. 1, pp. 23-32, 2007.

[12] N. C. Consoli, M. A. Vendruscolo, A. Fonini, and F. D. Rosa, "Fiber reinforcement effects on sand considering a wide cementation range," Geotextiles and Geomembranes, vol. 27, no. 3, pp. 196-203, 2009.

[13] N. C. Consoli, P. D. M. Prietto, and L. A. Ulbrich, "Influence of fiber and cement addition on behavior of sandy soil," Journal of 
Geotechnical and Geoenvironmental Engineering, vol. 124, no. 12, pp. 1211-1214, 1998.

[14] N. C. Consoli, M. A. Vendruscolo, and P. D. Marques Prietto, "Behavior of plate load tests on soil layers improved with cement and fiber," Journal of Geotechnical and Geoenvironmental Engineering, vol. 129, no. 1, pp. 96-101, 2003.

[15] C. J. Miller and S. Rifai, "Fiber reinforcement for waste containment soil liners," Journal of Environmental Engineering, vol. 130, no. 8, pp. 981-985, 2004.

[16] H. Ochiai, J. Otani, S. Hayashic, and T. Hirai, "The pullout resistance of geogrids in reinforced soil," Geotextiles and Geomembranes, vol. 14, no. 1, pp. 19-42, 1996.

[17] R. M. Bakeer, A. H. Abdel-Rahman, and P. J. Napolitano, "Geotextile friction mobilization during field pullout test," Geotextiles and Geomembranes, vol. 16, no. 2, pp. 73-85, 1998.

[18] G. L. Sivakumar Babu, A. Sridharan, and K. Kishore Babu, "Composite reinforcement for reinforced soil applications," Soils and Foundations, vol. 43, no. 2, pp. 123-128, 2003.

[19] T. Nakamura, T. Mitachi, and I. Ikeura, "Estimating method for the in-soil deformation behavior of geogrid based on the results of direct box shear test," Soils and Foundations, vol. 43, no. 1, pp. 47-57, 2003. 

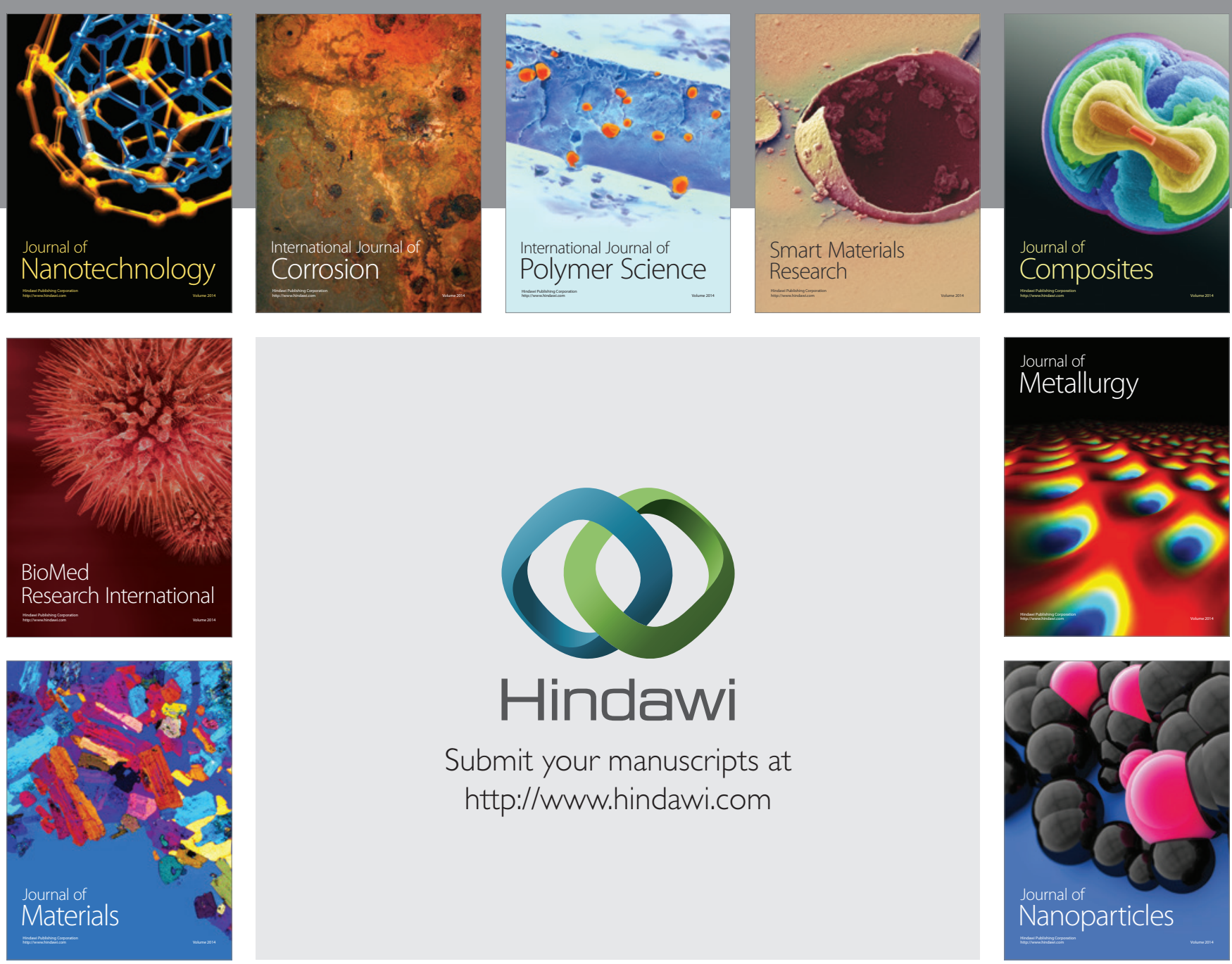

Submit your manuscripts at http://www.hindawi.com
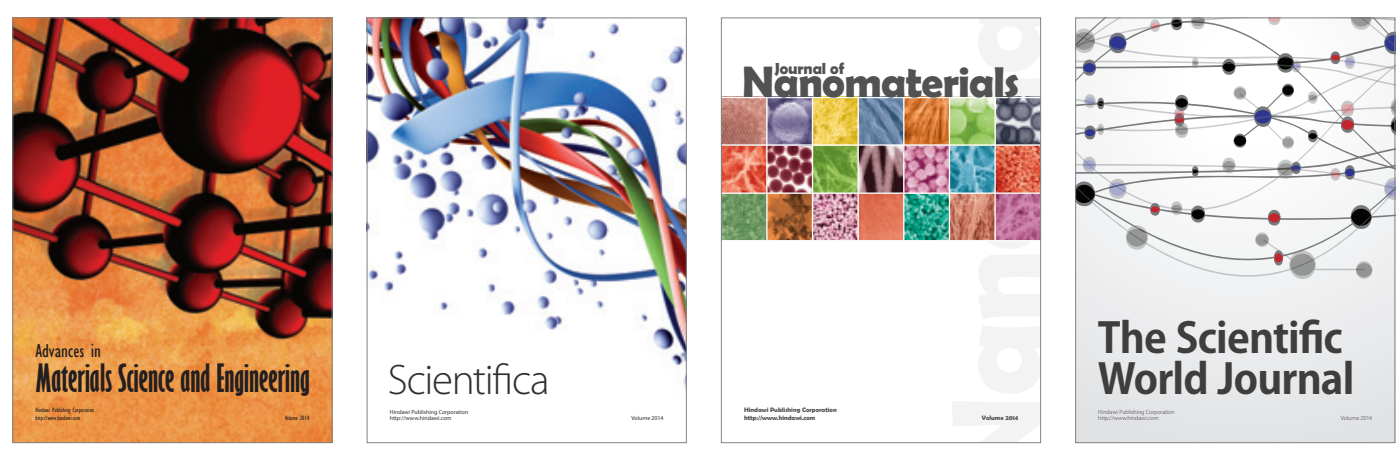

\section{The Scientific World Journal}
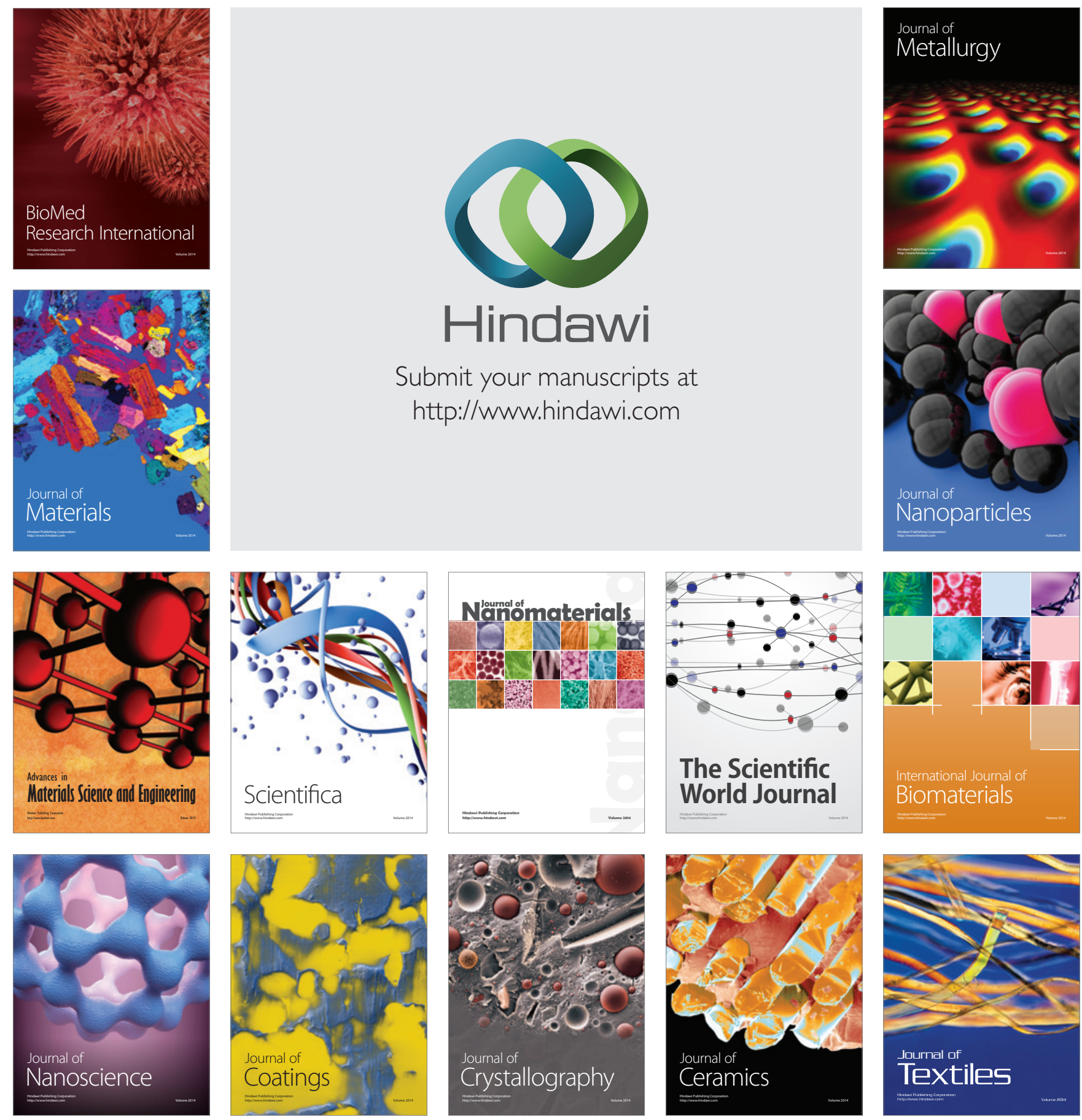